（4）ジャイロ・モーメントの振動特性に対する影 響はジェット・エンシンにおいても無視できない.し たがって, 多軸エンジンの場合は各軸の回転速度を考 虑してジャイロ・モーメントの項を計算し，振動特性 を求める必要がある.

この報告を終わるにあたり, 聊指導下さった当所原 動機部松木部長, 航空機公害研究グループ鳥崎総合研 究官に深く感謝の意を表します.

\section{考文献}

1) 松木, 鳥崎：リフト・シェット・エンジン JR $100 \mathrm{H}$
の概要, 機棫学会誌 70 巻 581 号 (昭和 42 年 6 月), p. 918 921.

2）宮地, 星谷, 祖父江: 単融シェット・エンジンの不つ りあい振動とダソパ轴受によるその防止，航空宇宙学 会誌, 本号 552 562.

3）松木，鳥崎：ファン・エンジンの動向，機械学会誌 73 巻 617 号 (昭和 45 年 6 月), p. 812 818.

4) 宮地, 小河, 星谷, 祖父江: ジェット・エンジン用薄 肉組立ロータの曲げ佣性, 航空宇宙技術研究所報告, TR-329 (1973 年 7 月).

5）宮地, 星谷, 祖父江: 第 15 回航空原動機講演会講演 集.

6) International Standard Organization: Proposed Draft ISO Recomendation: Balancing Criteria for Flexible Rotors.

\title{
ヘリコプター運動解析の仮定の検討* \\ An Examination of the Assumptions of the Helicopter Motion Analysis
}

加 藤 寛一郎**.山 根 隆 志***

Kan'ichiro Kato and Takashi Yamane

\begin{abstract}
Two major assumptions adopted in the current helicopter motion analysis are examined. It is shown numerically that to neglect the laterallongitudinal coupling motion may lead to about $20 \%$ error in the control response at lower frequencies, and that the quasi-static rotor assumption (or HOHENEMSER's assumption) can also produce about $20 \%$ error in the pitch damping at the frequency region of the short period mode. The coupling effect is remarkable for blades with large Lock number and is sensitive to the inflow distribution, while the effect of rotor dynamics is predominant for rotors with small Lock number or small rotational speed.
\end{abstract}

\section{1.はしがき}

ヘリコプターの運動方程式を微小摄乱理諭で記述し たとき，その空力微係数は，飛行試験加ら推定した值 と, 通常 2 割程度の相違を示す ${ }^{1)}$ ，乙のととは, 安定 増大装置や自動㙅絽装置を設計するとき，解析が信用 されない理由の一つになっている，相違の原因はいる いる考えられるが，今日常用されている運動方程式に 適用されている，次の二つの仮定を再検討してみる必 要があろう.すなわち, 胴体の縦運動・横運動は分離 して扱えること(非連成仮定)，および，ロータ運動

\footnotetext{
* 昭和 50 年 11 月飛行機シンポジウムで講演，昭和 51 年 2 月 6 日原稿受理

** 東京大学工学部航空学科

*** 東京大学大学院
}

を準定常とみなし得るとと(準定常ロータ，あるいは HOHENEMSER の仮定)である. ての運動方程式を初 めて定式化したと言わ机る HOHENEMSER ${ }^{23}$ 以来, 準 定常ロータの仮定については, KAUFMAN ら3) が周波 数応答を利用して，数值的保検討し， $\omega / \Omega \approx 0.1$ が適 用限界であることを示した，一方，非連成仮定に関し て, MILLER4) は特性根を検討しその妥当性を述べよ うとしたが，ZBROZEK ${ }^{57}$ はさらに検討が必要であると 付記して怙り，実際 SHULT2 ${ }^{1)}$ の解析を見ると，非連 成方程式は，必ずしも飛行試験之良い一致は示してい ない. 然るに現在では，このような事情はとすすれば 忘れられ，上記二つの仮定を用いた，固定翼機の場合 と同形の運動方程式か，その適用限界を越えて用いら れるととも稀ではない，本稿は, 関節型剛体ブレード の機体がホバリング状態にある場合, 特に空力微係数 に着目して，上記二つの仮定を再検討する．ただし， 空気力の非定常性は考虑されていない.

\section{記 号 (第 1 図参照)}

$$
\begin{aligned}
& A_{1 s}, B_{1 s} \text { : シャフトから見たサイクリック・ピッチ } \\
& \text { 角, } \theta_{s}=\theta_{0}-A_{1 s} \cos \Psi-B_{1 s} \sin \Psi \\
& a_{1}, b_{1} \quad \text { : 水平面から見たフラッピング角, } \\
& \beta=a_{0}-a_{3} \cos \Psi-b_{1} \sin \Psi
\end{aligned}
$$

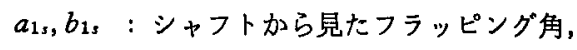

$$
\begin{aligned}
& \beta_{s}=a_{0}-a_{1 s} \cos \Psi-b_{1 s} \sin \Psi \\
& I_{y} \quad \text { : 機体のピッチ軸まわり慣性能率 } \\
& M \dot{\theta} \quad \text { ピッチ・ダンピング, (4), (5) 式参照 }
\end{aligned}
$$




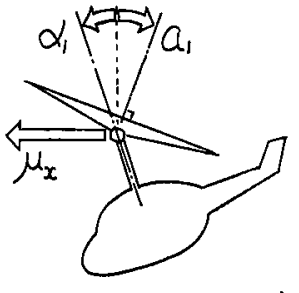

水平面

（a）左側面図 第 1 図 ホバリング時の 6 自由度

$\begin{array}{ll}\tilde{M} \dot{\theta} & : \text { 等価ピッチ・ダンピング, (7)式参照 } \\ s & : \text { ラプラス演算子 } \\ u, v & : \text { 機体固定系での機体重心の速度成分 } \\ \alpha_{1}, \alpha_{2} & : \text { 機体姦勢角, } \alpha_{1}=-\theta, \alpha_{2}=-\phi \\ \gamma & : \text { ロック数, } \gamma=\rho a c R^{4} / I_{1} \\ \theta, \phi & : \text { 機体のピッチ角およびバンク角 } \\ \mu_{x}, \mu_{y} & : \text { ロータ・ハブの無次元水平並進速度 } \\ \Omega & : \text { ロータ回転角速度 } \\ \omega & : \text { 円振動数 }\end{array}$

2. 運動方程式

解析の出発点として，文献 6) 195 頁に示された， ロータ・ダイナミックスも含めた，6元連立運動方程 式を用いる。これは翼素理論から導かれたもので，次 の形をしている.

$$
\begin{aligned}
& {\left[M_{6}(s)\right]\left\{\mu_{x}, \mu_{y}, \alpha_{1}, \alpha_{2}, a_{1}, b_{1}\right\}^{T}} \\
& \quad=\left[C_{6}\right]\left\{A_{1 s}, B_{1 s}\right\}^{T}
\end{aligned}
$$

ここに $\left(M_{6}\right],\left[C_{6}\right)$ はそれぞれ $6 \times 6,6 \times 2$ の係数行 列であり，方程式は静止采から記述されている．との 式に前述の二仮定を適用する.

【I】準定常ロータの仮定: $\dot{a}_{1}+\dot{\alpha}_{1}, \dot{b}_{1}+\dot{\alpha}_{2}$ 梪視(と れが HOHENEMSER の仮定と呼ばれる). 同 時にロー夕角加速度項 $\ddot{a}_{1}, \ddot{b}_{1}$ 無視.

【II】非連成仮定: $\mu_{y}, \alpha_{2}$ およびその微分項無視. こうして得られる，2 元連立運動方程式が，今日常用 されている式に相当する. 次式がそれで，同文献 6) 201 頁に示されている.

$$
\left\lceil M_{2}(s)\right]\left\{\mu_{x}, \alpha_{1}\right\}^{T}=\left\{C_{2}\right] B_{1 s}
$$

これに対し，【II】の仮定を適用しない，すなわち縦 横の連成を考虑した，4元連立運動方程式を導出して おいた。

$$
\begin{gathered}
\left\lceil M_{4}(s)\right]\left\{\mu_{x}, \mu_{y}, \alpha_{1}, \alpha_{2}\right\}^{T} \\
=\left[C_{4}\right]\left\{A_{1 s}, B_{1 s}\right\}^{T}
\end{gathered}
$$

機体固定系の変数に書き改めると，(2)，(3) 式はそ れぞれ次のようになり，下線部が連成項である.

$$
\left\{\begin{array}{l}
\left(s-X_{u}\right) u-\left(s^{2} X \ddot{\theta}+s X \dot{\theta}-g\right) \theta=g B_{1}, \\
-\left(s M_{u}+M_{u}\right) u+\left(s^{2}-s M_{\theta}\right) \theta=M_{B 1} B_{1},
\end{array}\right.
$$

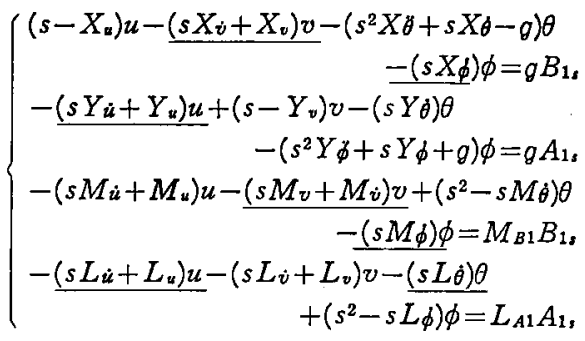

さててとで Sikorsky S-58 の諸元"゙用いて, (1)， (2)，(3) 式によるステップ操舵応答を訳算比較して みる. 結果は第 2 図(a)〜 (d)に示されており，非連

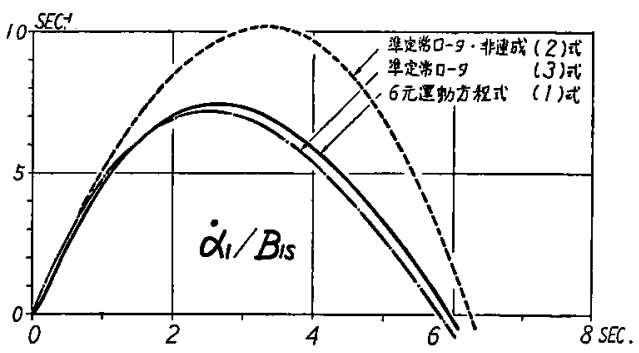

(a) ピッチ角速度

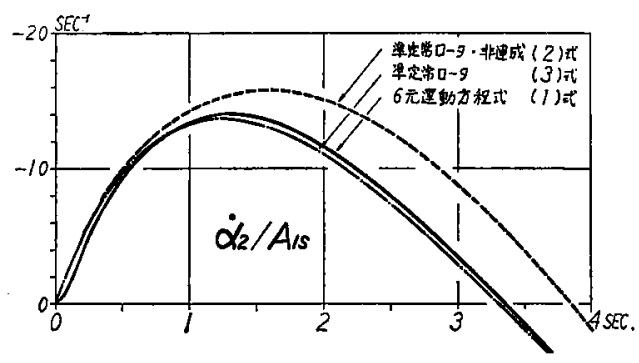

（b） ロール角速度

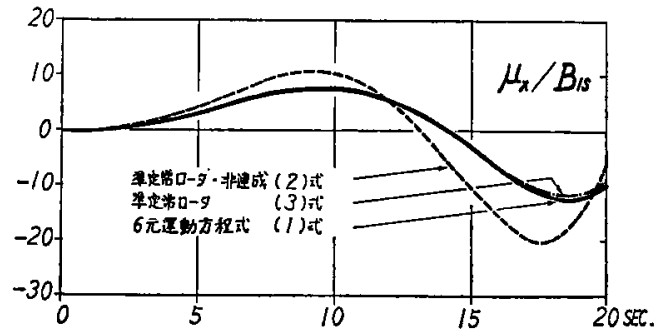

(c) 前進速度

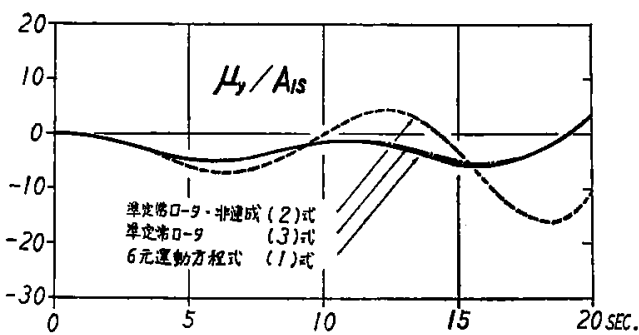

（d）左進速度

第2图 ステップ操舵応答 
第 1 表 運動方程式の特性根の比較

\begin{tabular}{c|c|c||c}
\hline 6 元方程式 (1) & 4 元方程式 (2) & 2 元方程式 (3) & 備 \\
\hline $0.121 \pm 0.368 i$ & $0.119 \pm 0.369 i$ & $0.139 \pm 0.382 i$ & 長周期モードの根 \\
$0.035 \pm 0.566 i$ & $0.034 \pm 0.562 i$ & $0.089 \pm 0.528 i$ & 上 \\
$-1.00 \pm 0.362 i$ & $-1.03 \pm 0.237 i$ & $-0.596 お よ ひ ゙-1.61$ & ロール・ピッチ減衰の根 \\
$-14.7 \pm 6.99 i$ & - & - & フラッピングの根 \\
$-15.3 \pm 40.4 i$ & - & - & 上 \\
\hline
\end{tabular}

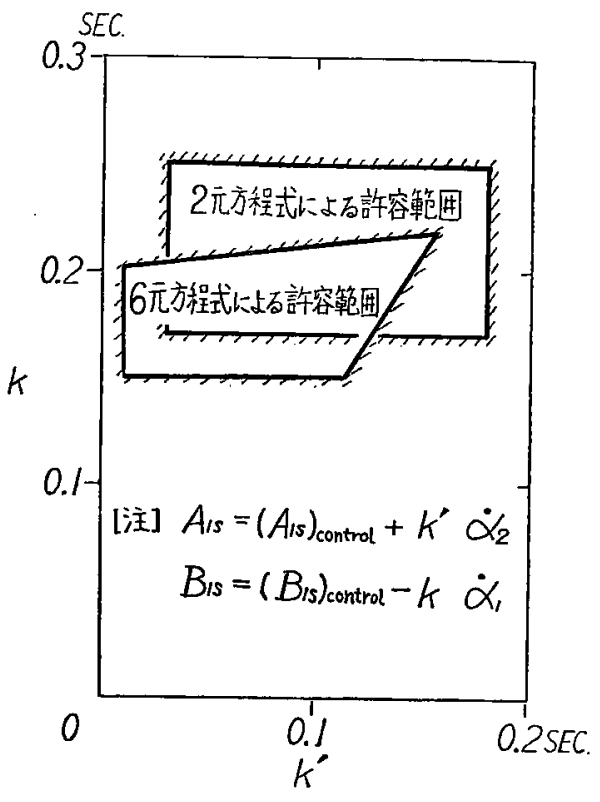

第 3 図角速度ダンパーのゲイン設計例

成を仮定した（2）式の振幅わよび周期に，かなりの 差か認められる．運動方程式の特性根にも，第 1 表に 示すとおり同様な差が認められ，特に注意を要するの は，(1)，(3) 式での 1 対の隇衰振動根が, 非連成を 仮定したために 2 実根（単調減衰根）に分裂している 点である．以上だけです，綎横連成運動の重要性が指 摘されよう。

実際，もし 6 元方程式 (1) と 2 元方程式 (2)を用い て, 所与条件を満足する角速度ダンパーを設計した場 合,ゲイン許容範围にどれ程差が出るかを第 3 図に示 した. 判定基準としては，MIL-F-83300 (V/STOL) Hover \& Low Speed, Level 18) を用いた. この図を 見ると，許容範囲が狭い割には相違が大であると言わ ねばなるまい。

\section{3. 周波数応答による検討}

運動方程式の精度を更に検討するため，以下，周波 数領域で考える. 第 4 図 (a) は， $\alpha_{1} / B_{1 s}\left(=-\theta / B_{1 s}\right)$ なる伝達関数，すなわちサイクリック・ピッチに対す る機体ピッチ角を， 2 元方程式と 4 元方程式とから求 めたあので，縦横連成の効果を比校するためのあので

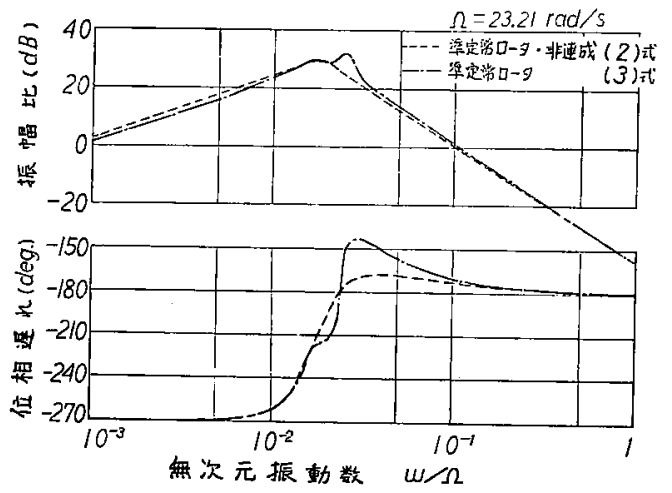

（a）絽横非連成の仮定の影響

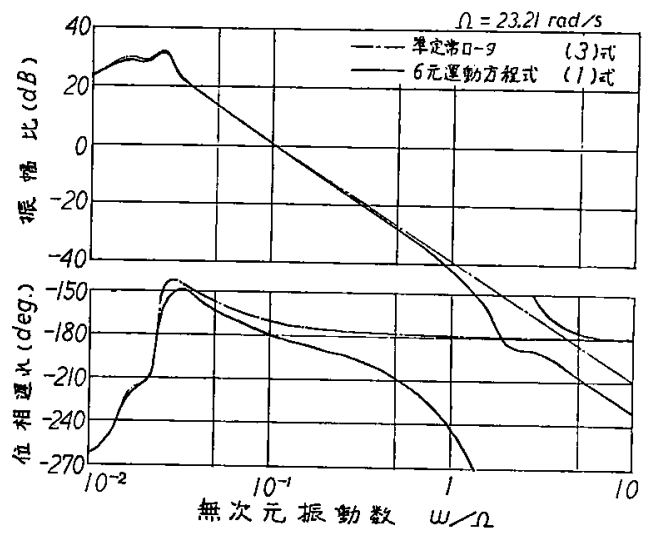

（b）準定常ロータの仮定の影響

第 4 図 サイクリック・ピッチ操舵に対する機体ピッチ 角の周波数応答

ある、一点銷線に見られる二つのピークは，実は胴体 の縦・横長周期モードに対応する掁動数であり，高周 波側のピークでは，横運動すなわち連成が激しく，両 曲線の差崖大である. 全般的に, 相異は $\omega / \Omega$ の小さ い所で認められ，連成勃果は低周波域で現われるとい える.

同図(b)は，同じく $\alpha_{1} / B_{1}$ を 6 元方程式と 4 元方 程式とから求め, 準定常口ー夕の仮定の影響を見た あのである. 注意すべきは， $-1 \mathrm{~dB}$ が振幅比にして -11\% を意味するととである.実際経験される周波 数箸囲内でも， $\omega / \Omega \cong 0.5$ になると振幅誤差は $10 \%$ 程度に達している，そもそも，準定常ロータの仮定之 

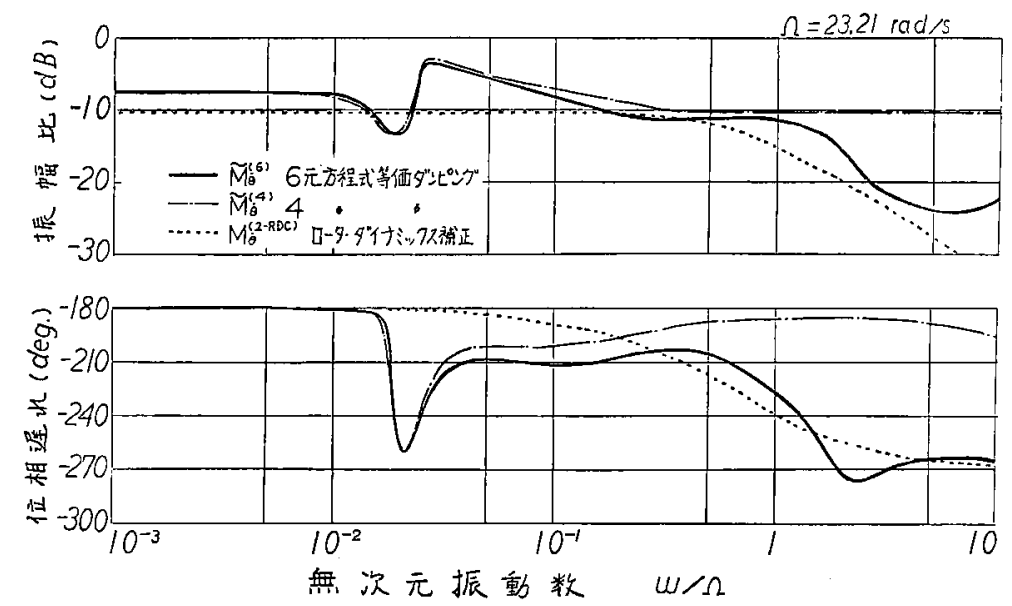

第 5 図 等価ピッチ・ダンピングの Bode 線図

は,

$$
\begin{aligned}
a_{1}+\alpha_{1} & =a_{1 s} \\
& =\frac{16 / \gamma \Omega}{1+16 s / \gamma \Omega}(s \theta) \cong-\frac{16}{\gamma \Omega}(s \theta)
\end{aligned}
$$

すなわち $1+(16 / \gamma \Omega) i \omega \cong 1$ と近似することに相当する ので, KAUFMAN ${ }^{3)}$ の言うように, $\omega / \Omega \approx 0.1$ が仮定 の有効限界であろう.たたし，6元方程式自体が，定 常空気力を用い，胴体に対しては無限枚のブレードを 考えているので, $\omega / \Omega \geqq 1$. では有効性を失うことあ 併記しておく.

次に第 5 図は，等価ピッチ・ダンピングを計算し比 較したあのである.まず， 6 元方程式（1）より $a_{1}$, $b_{1}, \mu_{y}, \alpha_{2}$ を消去すると，

$$
\left\{\begin{array}{l}
\left(s-\bar{X}_{u}(s)\right) u-\tilde{X} \dot{\theta}(s) \theta=\bar{X}_{B 1}(s) B_{1} \\
-\tilde{M}_{u}(s) u+\left(s^{2}-s \tilde{M} \theta(s)\right) \dot{\theta}=\tilde{M}_{B 1}(s) B_{1 s}
\end{array}\right.
$$

の形になり，等価ピッチ・ダンピング $\tilde{M} \dot{\theta}=\tilde{M} \dot{\theta}^{(6)}(s)$ が得られる. 次に，4元方程式 (5) より $v, \phi を$ を消 去すると，同形の表示式を得るが，このときの等価ダ ンピングを $\tilde{M} \dot{\theta}=\tilde{M}_{\dot{\theta}}^{(4)}(s)$ とする. さらに，2 元方程 式（4）のピッチ・ダンピングを $M \dot{\theta}=M \ddot{\theta}^{(2)}$ とかく と, この $M \theta^{(2)}$ は定数となり，非連成・準定常口ー タを仮定した，通常のピッチ・ダンピングである。乙 れに，いわゆるロータ・ダイナミックス補正"9)を施し たものを，

$$
M \dot{\theta}^{(2-R D C)}(s)=M \dot{\theta}^{(2)} /(1+16 s / r \Omega)
$$

で示すととにする.

第 5 図は，これら $\tilde{M}_{\dot{\theta}}^{(6)}, \tilde{M}_{\dot{\theta}}^{(4)}, M \theta^{(2-R D C)}$ を比較 したものである.高周波域 $(\omega / \Omega \gtrsim 1$.) での実線と一点 鎖線との顕著な差が，準定常ロータの仮定の影響であ り $\omega / \Omega \cong 0.2$ で振幅誤差は $2 \mathrm{~dB}$, 約 $20 \%$ に達して いる. 一方, 低周波域 $(\omega / \Omega \leqq 0.1)$ における実線・点
線の棖幅比の差が，連成効果であり，これはピッチ運

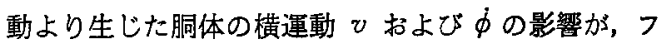
ィードバックされる勃果である.したがって，顸横の 連成効果を考える場合には，空力微係数を，ロータ単 独の運動加ら，

$$
M \dot{\theta}=\frac{1}{I_{v}}\left[\frac{\partial M}{\partial \dot{\theta}}+\frac{\partial M}{\partial a_{1 s}} \frac{\partial a_{1 s}}{\partial \dot{\theta}}+\frac{\partial M}{\partial b_{1 s}} \frac{\partial b_{1 s}}{\partial \dot{\theta}}\right]_{s=0}
$$

と推定するのでは不充分で，さらに機体の横運動 $v, \dot{\phi}$ を考虑して，横の運動方程式から， $\partial v / \partial \dot{\theta}, \partial \phi / \partial \dot{\theta}$ を求 め（7)式に対し,

$$
\tilde{M} \theta(s)=M \theta+\frac{1}{I_{v}}\left(\frac{\partial M}{\partial v} \frac{\partial v}{\partial \dot{\theta}}+\frac{\partial M}{\partial \dot{\phi}} \frac{\partial \phi}{\partial \dot{\theta}}\right)
$$

の值を用いるととが肝要である（10)式を用いない場 合は，4元方程式（5）または 6 元方程式（1）を用 いて，解析を行なうことが必要である.なお， $s=0$ の 場合, (10)式は

$$
\begin{aligned}
\tilde{M} \dot{\theta} & =M \dot{\theta}-M_{v} \frac{L_{\theta}}{L_{v}}-\left.M_{\phi} \frac{Y \dot{\theta}}{Y_{\phi}+g / s}\right|_{s=0} \\
& =M \dot{\theta}\left(1-M_{v} L \dot{\theta} / M_{\theta} L_{v}\right)
\end{aligned}
$$

\section{と書かれる。}

とのようにして得られた，(5) 式の $M_{\theta}, M_{\phi}$ およ び (11) 式の $\tilde{M} \dot{\theta}$ の数值を第 2 表 (®に示す. 表中の $\tilde{M} \theta / M \theta$ は，連成運動をしている状態での測定值と， 非連成を仮定した理論値との比と見るととあできる. なお， APPENDIX の概算によれば，

$$
\tilde{M} \dot{\theta} / M \dot{\theta} \approx 1+(\gamma / 16)^{2}
$$
となり，縦横連成にはロック数が效いているととがわ かる.とのととは，第2表からあ確かめられる.

\section{4. 他の吹下ろしモデル・他の機種での検討}

以上の計算は，すべて Sikorsky S-58 の諸元を用 い，吹下ろしは一様としていた．とこで，念のため文 
第 2 表 空力滋係数值の比較（ $\omega=0$ のとき）

\begin{tabular}{|c|c|c|c|c|c|c|c|}
\hline & 機 体 名 & $M \dot{\theta}$ & $M \phi$ & $\tilde{M} \theta$ & $\tilde{M} \theta / M \phi$ & ロック数 & 吹下ろしモデル \\
\hline (A) & Sikorsky S-58 & $-0.302 \mathrm{sec}^{-1}$ & $0.327 \mathrm{sec}^{-1}$ & $-0.434 \mathrm{sec}^{-1}$ & 1.44 & 10.60 & 一＼cjkstart様 \\
\hline (B) & 同 上 & -0.454 & 0.275 & -0.517 & 1.14 & 同上 & 非 一 様101 \\
\hline (C) & Hughes 500 & -1.412 & 0.625 & -1.541 & 1.09 & 5.62 & 一＼cjkstart様 \\
\hline
\end{tabular}

献 10）に従って，円錐状の吹下ろしを仮定し，空力微 係数を計算し直してみる. 結果は第 2 表队のようにな り，連成効果は吹下ろし分布に敏感であることがわか る.

また，縱横連成は機種にもよることが充分考えられ るので, 比較的小型の Hughes 500 クラスの機体に ついて，一様吹下ろし仮定のもとで計算した結果が同 表さである.乙の場合，連成は比较的弱いが，なお $9 \%$ 程度の誤差を生じうる。

\section{5.むすび}

ホバリング時の関節型ロータ・ヘリコプターの運動 解析における仮定について検討を行ない，現在常用さ れている縦横非連成・準定常ロータの仮定は必ずしす 適当でないととを示した. (12)式によれば，ロック数 $r$ の大きい機体などでは，低周波域で縦横連成の影響 が大であることが考えられる. 文献 1)，5）の飛行試験 結果之理論值との相異の傾向が, 第 2 四の傾向と一致 しており，てのことと関連があるのではないかと思わ れる. また，準定常ロータの仮定については，安定增 大装置を装備した機体では， $\omega / 8 \cong 0.3$ 程度になるこ とが稀ではなく，空力微係数の誤差が $20 \%$ 近くに達 しうる. 実際, ヘリコプターのダンピング微係数を， 短周期モードの操舵応答データから推定すると，計算 值 $M \dot{\theta}^{(2)}$ の 80 90\% 程度の值になることは，しばし ば経験されることである．したがって，(6)式から推 定されるように，特に $\gamma \times \Omega$ の小さい機体では，準定 常ロータの扱いに注意すべきであろう。

最後に, 貴重な助言を賜わった, 東京大学宇宙航空 研究所の東昭教授，ならびに川崎重工航空機事業部の 宮嶋克行氏・大沢俊之氏に深く感謝の意を表する.

\section{参考文 献}

1) Schurtz, E.R.: The Determination of Helicopter Longitudinal Stability Derivatives from Flight Test Data, Part 3, WADC Technical Report 55$438(1959 / 9)$.

2) Hohenemser, K.: Dynamic Stability of a Helicopter with Hinged Rotor Blades, NACA TM 907 (1938).

3) Kaugman, L. and Peress, K. : A Review of Methods for Predicting Helicopter Longitudinal Response, JAS, Vol. 23-3 (1956/3) pp. 259-271.

4) MilLeR, R. H.: Helicopter Control and Stability in Hovering Flight, JAS, Vol. 15-8 (1948/8) pp.
453-472.

5) ZBROZEK, J.: Investigation of Lateral and Directional Behaviour of Single Rotor Helicopter (Hoverfly Mk. 1), R \& M 2509 (1948).

6) Nrkolsky, A.A.: Helicopter Analysis, Wiley (1951)

7) SECKEL, E.: Stability and Control of Airplanes and Helicopters, Academic Press (1964) p. 456.

8) Chalk, C. R., Key, D. L., Kroll, J. Jr., Wasserman, R. and RADFORD, R. C.: Background Information and User Guide for MIL-F-83300, Military Specification-Flying Qualities of Piloted V/STOL Aircraft, AFFDL-TR-70-88 (1971/3) pp. 78-238.

9) Ellis, C. W. : Effect of Articulated Rotor Dynamics on Helicopter Automatic Control System Requirements, Aero. Eng. Rev. Vol. 12-7 (1953/7) pp. 30-38.

10) Azuma, A, and Nakamura, Y.: Pitch Damping of Helicopter Rotor with Nonuniform Inflow, J. Aircraft Vol. 11-10 (1974/10) pp. 639-646.

\section{APPENDIX 等価ピッチ・ダンピングの㯕算}

定性的把握のために，等価ピッチ・ダンピング $\tilde{M}_{\theta}$

の概算をする．周波数 $\omega=0$ のときには(11)式より。

$$
\begin{aligned}
\tilde{M} \dot{\theta} / M \dot{\theta} & =1-M_{0} L \dot{\theta} / M \dot{\theta} L_{v} \\
& =1-M_{v} M_{\phi} / M \dot{\theta} M_{\mathbf{v}}
\end{aligned}
$$

ここで, $\mu_{v}=0$ とおいた次のフラッピング方程式,

$$
\left\{\begin{aligned}
a_{0} & =(\gamma / 8)\left(\theta_{0}+4 \lambda_{a} / 3\right) \\
& \cong(3 \gamma / 8)\left(2 c_{T} / a \sigma\right) \\
a_{1 s} & =\mu_{x}\left(8 \theta_{0} / 3+2 \lambda_{a}\right)-(16 / \gamma \Omega) \dot{\theta}+(1 / \Omega) \phi \\
b_{1 s} & =(4 / 3) \mu_{x} a_{0}-(16 / \gamma \Omega) \phi-(1 / \Omega) \dot{\theta}
\end{aligned}\right.
$$

および,

$$
\begin{aligned}
2 c_{T} / a \sigma & =\theta_{0} / 3+\lambda_{a} / 2 \\
\lambda_{a} & =-\sqrt{c_{T} / 2}
\end{aligned}
$$

ことに, $c_{r} \equiv T / \pi \rho \Omega^{2} R^{4}, \sigma \equiv b c / \pi R$

を用いて， $M_{\phi} / M g$ および $M_{v} / M_{\mathbf{z}}$ を概算すると，

$$
\begin{aligned}
& M_{\hat{\theta}} \cong \frac{1}{I_{y}} \frac{\partial M}{\partial a_{1 s}} \frac{\partial a_{1 s}}{\partial \dot{\theta}}, \quad M_{\phi} \cong \frac{1}{I_{v}} \frac{\partial M}{\partial a_{1 s}} \frac{\partial a_{1 s}}{\partial \phi} \\
& \frac{M \phi}{M \dot{\theta}} \cong \frac{\partial a_{1 s} / \partial \phi}{\partial a_{1 s} / \partial \dot{\theta}}=-\frac{\gamma}{16},
\end{aligned}
$$

また，

$$
\begin{aligned}
M_{w} & \cong \frac{1}{I_{y}} \frac{\partial M}{\partial a_{1 s}} \frac{\partial a_{1 s}}{\partial u}, M_{v} \cong \frac{1}{I_{y}} \frac{\partial M}{\partial a_{1 s}} \frac{\partial a_{1 s}}{\partial v} \\
\frac{M_{v}}{M_{u}} & \cong \frac{\partial a_{1_{s}} / \partial v}{\partial a_{1 s} / \partial u} \cong \frac{\partial b_{1 s} / \partial \mu_{x}}{\partial a_{1 s} / \partial \mu_{x}} \\
& =\frac{4 a_{0} / 3}{8 \theta_{0} / 3+2 \lambda_{s}} \cong \frac{\gamma}{16} \frac{2 c_{T} / a \sigma}{2 c_{T} / a \sigma-\lambda_{s} / 4} \\
& \cong \gamma / 16
\end{aligned}
$$

(i), (iii), (iv) 上り, $\omega=0$ のとき,

$$
\tilde{M} \theta / M \theta \approx 1+(\gamma / 16)^{2}
$$

